\title{
Rotary Friction Welding of Dissimilar Joints between SSM356 and SSM6061 Aluminium Alloys Produced by GISS
}

\author{
Suppachai Chainarong ${ }^{1, *}$, Chaiyoot Meengam ${ }^{1}$, and Muhamad Tehyo ${ }^{2}$ \\ 1 Department of Engineering, Faculty of Industrial Technology, Songkhla Rajabhat University, Songkhla \\ 90000, Thailand \\ 2 Department of Industrial Engineering, Faculty of Engineering, Princess of Naradhiwas University, \\ Naradhiwad 96000, Thailand \\ *E-mail: Suppachai.ch@skru.ac.th
}

\begin{abstract}
The objective of research to investigate the parameters, microstructure and mechanical properties of butt joint SSM356 with SSM6061 aluminum alloy by using RFW processes. The main parameters such as rotation speeds are 1550, 1700 and $1850 \mathrm{rpm}$, burn-off length are 2, 2.5 and $3 \mathrm{~mm}$ respectively. For experiment found that, both materials have weld ability to get along well though it has a different chemical composition, the changes in welded metals microstructures occurs deformation leads to smaller particle size. The average dimensions of $\mathrm{Mg}_{2} \mathrm{Si}$ particles were measured at $0.998 \mu \mathrm{m}$ long and 1.021 $\mu \mathrm{m}$ wide when one of the workpiece was rotated at $1850 \mathrm{rpm}$ with $2.5 \mathrm{~mm}$ burn-off length. The maximum average tensile strength is $87.24 \mathrm{MPa}$, efficiency of the weld joints is 51.89 percent compared with the base metal of SSM356 aluminum alloys, (base metal is 168.12 $\mathrm{MPa}$ ) and efficiency of the weld joints is 68.45 percent compared with the base metal of SSM6061 aluminum alloys (base metal is $127.44 \mathrm{MPa}$ ). Furthermore, small particles distributed in the weld metal promotes increasing hardness property up to $65.56 \mathrm{HV}$ in the weld metal as compared with those of the base metals.
\end{abstract}

Keywords: SSM356 and SSM6061 aluminum alloy, rotary friction welding, dissimilar joining.

ENGINEERING JOURNAL Volume 21 Issue 1

Received 4 April 2016

Accepted 1 July 2016

Published 31 January 2017

Online at http://www.engj.org/

DOI:10.4186/ej.2017.21.1.181 


\section{Introduction}

Rotary Friction Welding (RFW) process, one of the method is solid state welding, was developed from a friction stir welding (FSW) relying on heat input from the friction between the surfaces of the workpiece. In the RFW process, one of the workpiece is kept stationary and the other workpiece is rotating to generate heat, which makes the workpiece soften and lead them bond together. This basic principle of the FW process is illustrated in Fig. 1. The important parameters for RFW include rotation speed $(\mathrm{pmm})$, upset pressure $(\mathrm{N})$, friction time (second), burn-off length $(\mathrm{mm})$, and surface of workpiece etc,. The parameters for continuous drive RFW is illustrated in Fig. 2. For RFW, there are many advantages including excellent quality joints of the product, low distortion, non-filler, short weld time, ecologically friendly, energy efficient and little changes in the welded zone [1-2]. However, this RFW method also has some limits for welding. For instance, welding workpiece with a complex shape can be very difficult, or workpiece length become shortened after welding [3]. These usually occur when welding workpiece at low melting point because the heat input from the welding place is not sufficient and the upset pressure while welding is not high enough. Over the past several years, non-ferrous materials such as titanium alloy [4], magnesium alloy [5-7] and aluminum alloy [8-12] turn popular to this RFW method because it is widely used, especially aluminum alloy in automotive industry, marine industry and the aircraft industry [13]. Aluminum-Silicon was used in this industry because of its high strength, lightweight and corrosion resistance. However, common welding aluminum is not too easy because the oxide films often cracking of the weld metal [14], especially welding of dissimilar joint materials. This may affect the mechanical properties of the weld metal. However, using this RFW still has some limitations because this welding technique does not may not create enough high heat input. Only $60-80$ percent of heat input was produced comparing with the melting point of the materials [15] which may cause cracking in the weld metal.

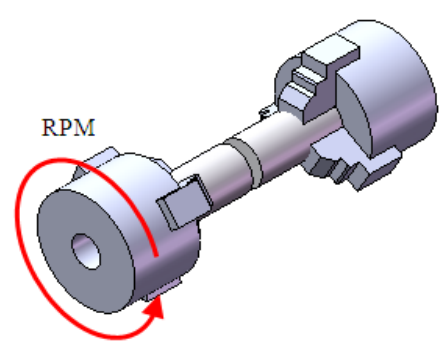

A. Period of approximation

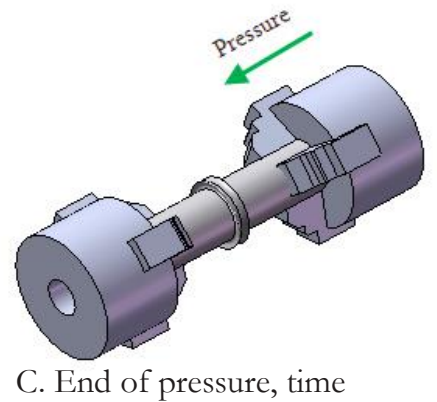

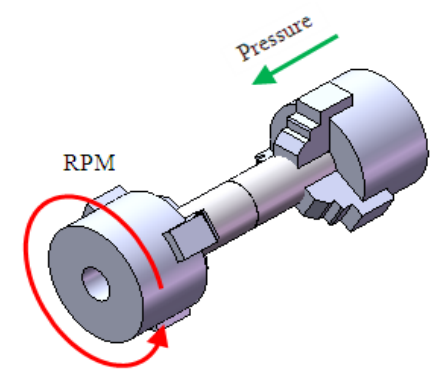

B. Pressure, time application

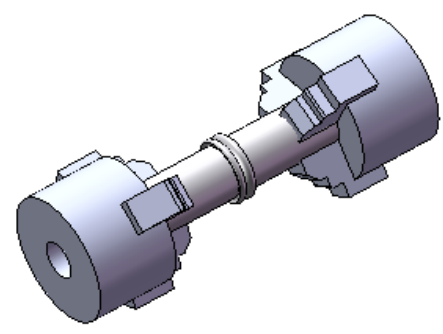

D. Finish welding

Fig. 1. The phases of the RFW process.

In this research, we study dissimilar joined materials between SSM356 aluminum-magnesium-silicon $(0.32 \% \mathrm{Mg}, 7.74 \% \mathrm{Si})$ with SSM6061 aluminum-magnesium-silicon $(1.2 \% \mathrm{Mg}, 0.8 \% \mathrm{Si})$ by using RFW process and the results were analyzed and presented. After RFW, the process was optimized by adjusting the rotation speed and burn-off length and analyzed in the welded metal $(W M)$, thermal mechanical affect zone (TMAZ) and the base metal (BM) by optical microscopy (OM), scanning electron microscopy (SEM). We expect that the mechanical properties test of tensile strength, the resistance of the weld metal, and Vickers microhardness test could be significantly improved. 


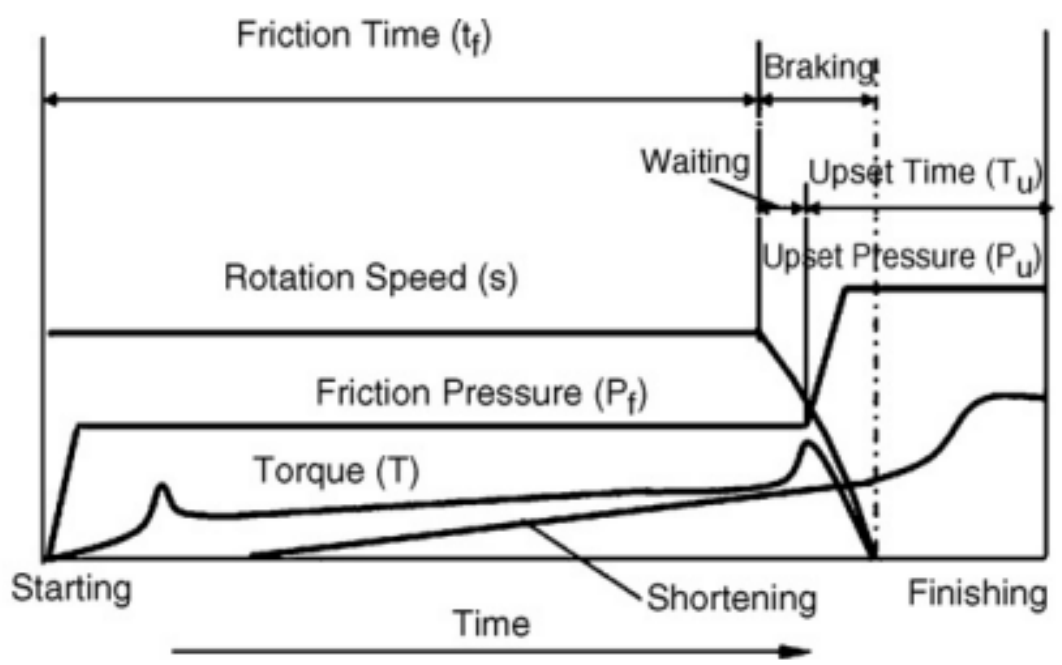

Fig. 2. Parameters for continuous drive RFW. [16]

\section{Experimental Procedures}

\subsection{Semi-Solid Metal Aluminum Alloys}

The materials for this experimentation are SSM356 aluminum alloy and SSM6061 aluminum alloy. Their chemical composition are shown in Table 1. These aluminum alloys were formed by Gas Induced Semi Solid (GISS) casting technique [17]. The specimens were machined as a cylindrical shape with the dimension at $\varnothing 12 \mathrm{~mm}$ and $50 \mathrm{~mm}$ in length as illustrated in Fig. 3. The workpiece preparation was carried out by grinding surfaces with $\mathrm{P} 1000$ grit SiC paper and cleaning with acetone for 3 minutes to eliminate alumina oxide film $\left(\mathrm{Al}_{2} \mathrm{O}_{3}\right)$, which $\mathrm{Al}_{2} \mathrm{O}_{3}$ can block heat input.

Table 1. Chemical composition of SSM356 and SSM6061 aluminum alloy.

\begin{tabular}{ccccccccc}
\hline Materials & Si & Fe & $\mathbf{C u}$ & $\mathbf{M n}$ & $\mathbf{M g}$ & $\mathbf{Z n}$ & $\mathbf{T i}$ & Al \\
\hline $\mathbf{3 5 6}$ & 7.74 & 0.57 & 0.05 & 0.06 & 0.32 & 0.01 & 0.05 & Bal. \\
$\mathbf{6 0 6 1}$ & 0.40 & 0.70 & 0.18 & 0.15 & 0.80 & 0.25 & 0.15 & Bal. \\
\hline
\end{tabular}

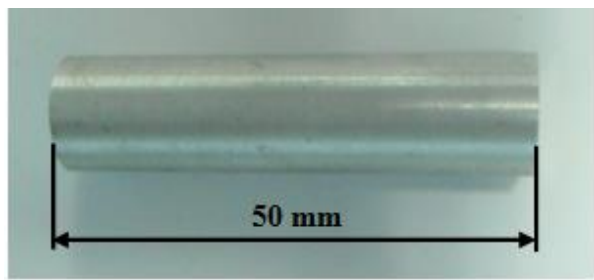

Fig. 3. The length of specimens for experiments of RFW.

\subsection{Method}

According to preliminary experiments and the parameters used in RFW process such as rotation per minute, burn-off length, and friction time, we found that the proper rotation speed ranging from 1550 to $1900 \mathrm{rpm}$ in order to bond the specimens. Therefore, we determine rotation speed in the RFW process as shown in Table 2. For the RFW process, lathe machine was adapted and applied for this RFW process because its stability and precision. Before starting the process, SSM6061 aluminum alloy is on the spinning side and SSM356 aluminum alloy is on stationary side as clockwise direction. Both of them are clamped by chuck. Then, turning on the rotation speed and compressed both surfaces of the workpieces together. The 
friction forces resulting heat input was generated leading to the plastic deformation until material mixed together.

Table 2. Parameters of the RFW process between SSM356 with SSM6061 aluminum alloy.

\begin{tabular}{|c|c|c|}
\hline \multicolumn{3}{|c|}{ Parameters } \\
\hline Rotational Speed (rpm) & Burn-off Length (mm) & Friction Time (sec) \\
\hline \multirow{3}{*}{1550} & 2 & \multirow{9}{*}{15} \\
\hline & 2.5 & \\
\hline & 3 & \\
\hline \multirow{3}{*}{1700} & 2 & \\
\hline & 2.5 & \\
\hline & 3 & \\
\hline \multirow{3}{*}{1850} & 2 & \\
\hline & 2.5 & \\
\hline & 3 & \\
\hline
\end{tabular}

\subsection{Metallurgy and Mechanical Properties Test}

The workpiece after RFW process was put to the tensile test follow: ASTM 370-02a standards, which were tested at room temperature and were tested for the tensile strength using the brand of testomatic testing machine. Vickers microhardness test follow: Zwick/Roell. Workpiece be tested with the diamond at $10 \mathrm{HV}$ and dwell time 10 second, respectively. Some workpiece be taken to prepare for the metallurgical analysis by optical microscopy and scanning electron microscopy FEI-Quanta, was supported by the Scientific Equipment Center, Prince of Songkla University. Which workpiece mounting with resin and machined with lathe to the middle of workpiece were polished by grinding on with P320, 400, 600, 800, 1000 and 1200 grit $\mathrm{SiC}$ paper, respectively. The workpieces were polished by alumina powder at 3,1 and $0.5 \mu \mathrm{m}$ and etched with Keller's reagent to reveal grain structures in the weld metal, thermal mechanical affect zone and base metal zone.

\section{Result and Discussion}

\subsection{Microstructure of Weld Metal}

Figure 4 shows the microstructure of the welded joints, taken at 50X by optical microscopy. The SSM356 aluminum alloy is on the left side and SSM6061 aluminum alloy is on the right side. The base microstructure of SSM356 aluminum alloy is illustrated in Fig. 4(j) and the base microstructure of SSM6061 aluminum alloy is illustrated in Fig. 4(k) which both materials form a globular structure. It is clearly see that in all the parameters of the experiment affect globular grains, which these globular grains are permanently destroyed by RFW plastic deformation process. For the rotation speed lower at $1550 \mathrm{rpm}$ and burn-off length at $2 \mathrm{~mm}$ illustrated in Fig. 4(a), it possibly make risk of the workpiece not adhere well due to the very low heat input during welding process which did not allow the softening material formation [8] and which allowed more voids after RFW process. It is noteworthy that, when the researcher steadily increased the burn-off length at 2.5 to $3 \mathrm{~mm}$, the resulting void became narrower because the texture of material has a higher density illustrated in Fig. 4(b, c). Moreover, the amount of voids tended to be decreased when the rotation speed during RFW process was increased. For example, when we added the rotation speed from 1550 to $1850 \mathrm{rpm}$, it showed that the voids are eliminated until depleted illustrated in Figs. 4(g, h, i) respectively. Likewise, as the rotation speed or burn-off length increased, flash was produced at the joint due to metal flow of both alloys in the weld metal caused by the rotational friction force [10]. However, a defect that happens to workpiece after RFW process worsens the mechanical properties of the workpiece [18]. The heating from the welding takes place only in the weld metal and thermal mechanical affect zone because such areas caused friction between two pieces of the workpiece surface. The structure in the weld metal and thermal mechanical affect zone was changed by rotation speed at $1700 \mathrm{rpm}$ with $2 \mathrm{~mm}$ burn-off length, not enough heat input, illustrated in Fig. 4(d). However, when the burn-off length was changed 
from 2.5 to $3 \mathrm{~mm}$, it can makes the complete joint illustrated in Figs. 4(e, f). However, there are possibilities to weld different types of aluminum alloy between SSM356 with SSM6061 aluminum alloy. Because, after examining the microstructure of some parameters illustrated in Figs. 4(e, f, g, h, i), there clearly shows that most of the weld metal adhere together and there is just little area that cannot be bonded together as micro void.

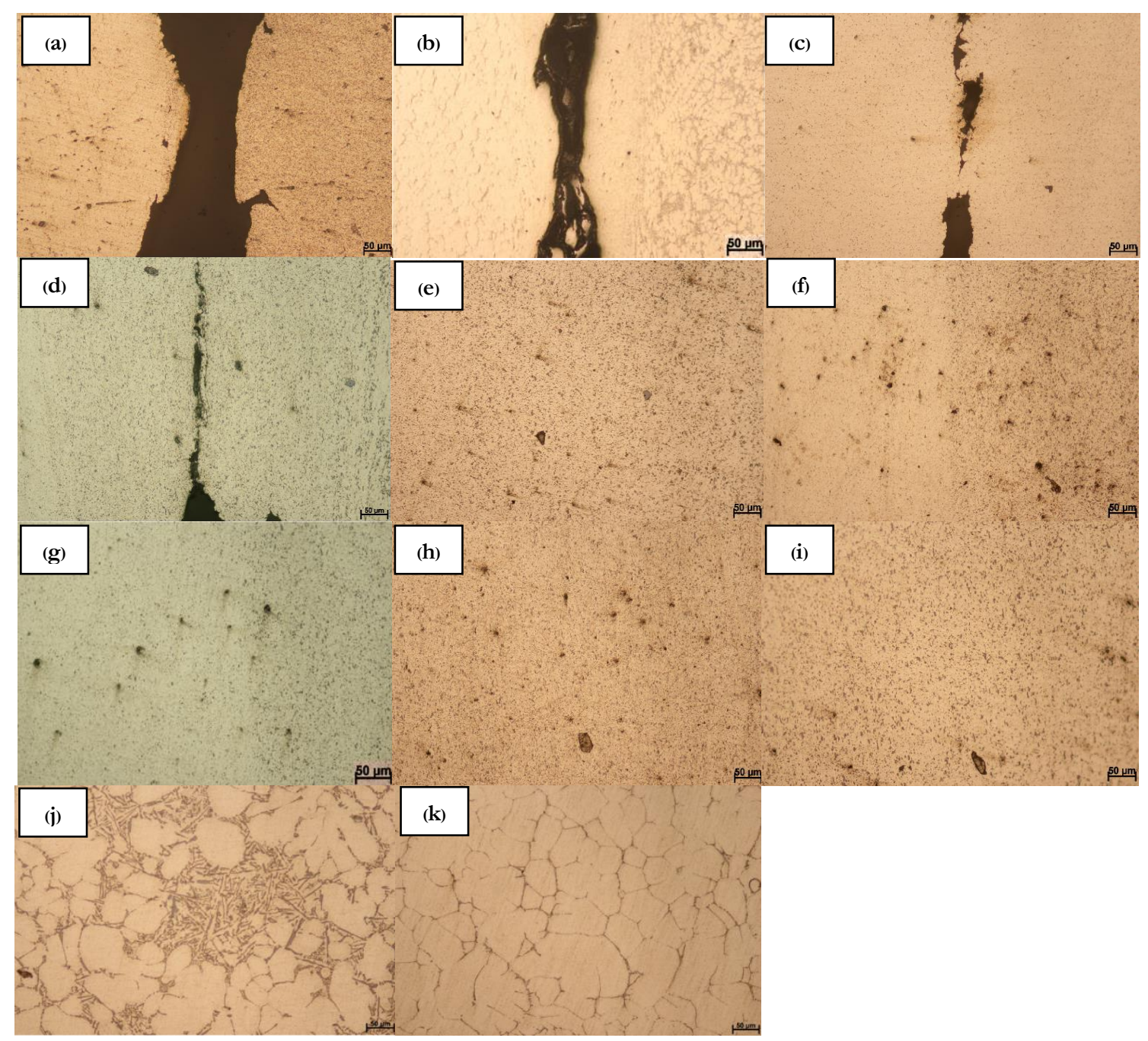

Fig. 4. Macrostructure of SSM356 with SSM6061 aluminum alloy in weld metal (a) $1500 \mathrm{rpm}$ at $2 \mathrm{~mm}$ burn-off length, (b) $1500 \mathrm{rpm}$ at $2.5 \mathrm{~mm}$ burn-off length, (c) $1500 \mathrm{rpm}$ at $3 \mathrm{~mm}$ burn-off length, (d) 1700 rpm at $2 \mathrm{~mm}$ burn-off length, (e) $1700 \mathrm{rpm}$ at $2.5 \mathrm{~mm}$ burn-off length, (f) $1700 \mathrm{rpm}$ at $3 \mathrm{~mm}$ burn-off length, (g) $1850 \mathrm{rpm}$ at $2 \mathrm{~mm}$ burn-off length, (h) $1850 \mathrm{rpm}$ at $2.5 \mathrm{~mm}$ burn-off length, (i) $1850 \mathrm{rpm}$ at 3 $\mathrm{mm}$ burn-off length, (j) base metal structure of SSM356, and (k) base metal structure of SSM6061.

\subsection{Particle Size in Weld Metal by SEM}

The photograph of SEM was taken at 3000X to determine the distribution and particle size of $\mathrm{Mg}_{2} \mathrm{Si}$ phase illustrated in Fig. 5. Besides, the defect, the distribution of particles and the particle size definitely affect the mechanical properties. If the particles are small and uniformly dispersed throughout the weld metal, it will result in a workpiece with good mechanical properties. According to the further inspection, it was found that each of the welding parameters will affect the uneven distribution of the particles. But, it was also found that the particles of the workpiece after welding formed a smaller size for all experiments because the pressure of the friction particles were destroyed and definitively leads to a smaller particle size. Additionally, the oxide film $\left(\mathrm{Al}_{2} \mathrm{O}_{3}\right)$ will hinder heat input in order to break the $\mathrm{Mg}_{2} \mathrm{Si}$ phase [19]. In the welding the rotation speed at $1550 \mathrm{rpm}$, it showed the average particle size of $1.573 \mu \mathrm{m}$ in length and the width of 0.876 
$\mu \mathrm{m}$, which distributed all around the weld metal zone. The particles are shaped as plate-like structure illustrated in Fig. 5(a). It was also found small cracks caused from the contraction of the weld metal. When the rotation speed increased to $1700 \mathrm{rpm}$, we found that the smaller particle size by average of $1.450 \mu \mathrm{m}$ in length and the width of $1.084 \mu \mathrm{m}$ illustrated in Fig. 5(b). With a similar welding, rotation speed at $1850 \mathrm{rpm}$, the particle sizes are small and dispersed throughout the weld metal zone illustrated in Fig. 5(c). The average size of such particle is $0.998 \mu \mathrm{m}$ long and $1.021 \mu \mathrm{m}$ wide, which is very small compared with other parameters. The particle size changes are caused by breaking and deformation behavior in the form of $\mathrm{Mg}_{2} \mathrm{Si}$ phase. Moreover, the distribution of broken small particles of $\mathrm{Mg}_{2} \mathrm{Si}$ phase results hardness properties to be increased as well because the distribution of such particles across the weld metal makes compressive strength become stronger.

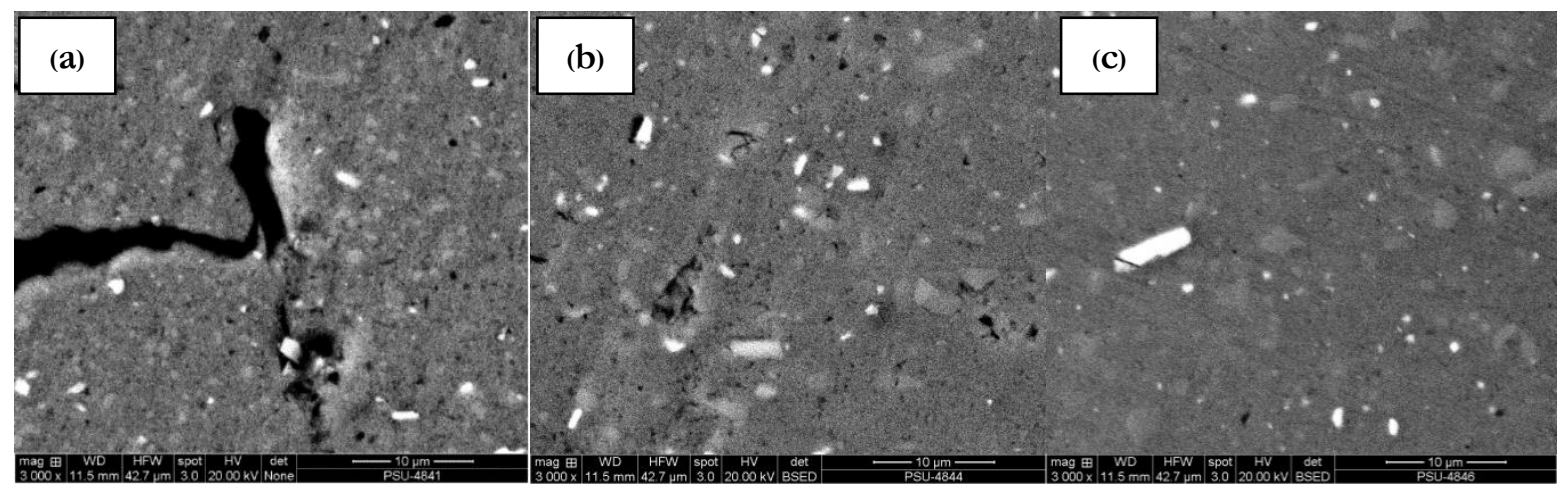

Fig. 5. Distribution of particle in weld metal (a) at $1550 \mathrm{rpm}$ and $2 \mathrm{~mm}$ burn-off length, (b) at $1700 \mathrm{rpm}$ and $2.5 \mathrm{~mm}$ burn-off length, and (c) at $1850 \mathrm{rpm}$ and $3 \mathrm{~mm}$ burn-off length.

\subsection{Result of Tensile Strength}

Figure 6 shows the tensile strength of SSM356 with SSM6061 aluminum alloy after RFW process. It was found that the rotation speed at $1850 \mathrm{rpm}$ and the burn-off length at $2.5 \mathrm{~mm}$ generates the maximum average tensile strength at $87.24 \mathrm{MPa}$. The efficiency of the weld joints is 51.89 percent compared with the base metal of SSM356 aluminum alloys with its tensile strength at $168.12 \mathrm{MPa}$. Moreover, efficiency of the weld joints is 68.45 percent compared with the base metal of SSM6061 aluminum alloys as tensile strength is $127.44 \mathrm{MPa}$. Meanwhile, the minimum average tensile strength is $54.38 \mathrm{MPa}$ from the workpiece with the rotation speed at $1550 \mathrm{rpm}$ and burn-off length at $2 \mathrm{~mm}$. This results efficiency of the weld joints at 32.35 percent compared with the tensile strength of base metal of SSM356 aluminum alloys and 42.67 percent compared with the tensile strength of base metal of SSM6061 aluminum alloys. However, in the comparison between two different burn-off length, the lower tensile strength is observed at $2 \mathrm{~mm}$ burn-off length and the higher tensile strength is likely to be produced when we increase the burn-off length to 2.5 $\mathrm{mm}$. However, the tensile strength value was less when burn-off length at $3 \mathrm{~mm}$ was used. This is because weld area is compressed into a small space leading too much flash and causing the lower tensile strength [20]. Moreover, defects that happened after welding also resulted in low tension as well [21]. All in this experiment, all workpiece can be bonded together with RFW process with rotation speed at $1550 \mathrm{rpm}$ and burn-off length at 2.5 and $3 \mathrm{~mm}$. At these parameter conditions, it can provide average tensile strength at 81.91 and $70.63 \mathrm{MPa}$ respectively. For the rotation speed at $1700 \mathrm{rpm}$ and burn-off length at 2, 2.5 and 3 $\mathrm{mm}$, we found that their average tensile strength are $66.60,82.61$ and $80.15 \mathrm{MPa}$ respectively. Finally, the rotation speed at $1850 \mathrm{rpm}$ and burn-off length at 2 and $3 \mathrm{~mm}$ can give the tensile strength at 57.45 and $71.60 \mathrm{MPa}$. It is noteworthy that parameters in the experiment will differently result in a completed workpiece which can be ascertained by the microstructure. The equation used to calculate the joint efficiency is given as:

$$
\text { Joint efficiency of RFW }=\frac{\text { UTS of bonded workpiece }}{\text { UTS of base SSM356 or SSM6061 aluminum alloy }} \times 100 \%
$$




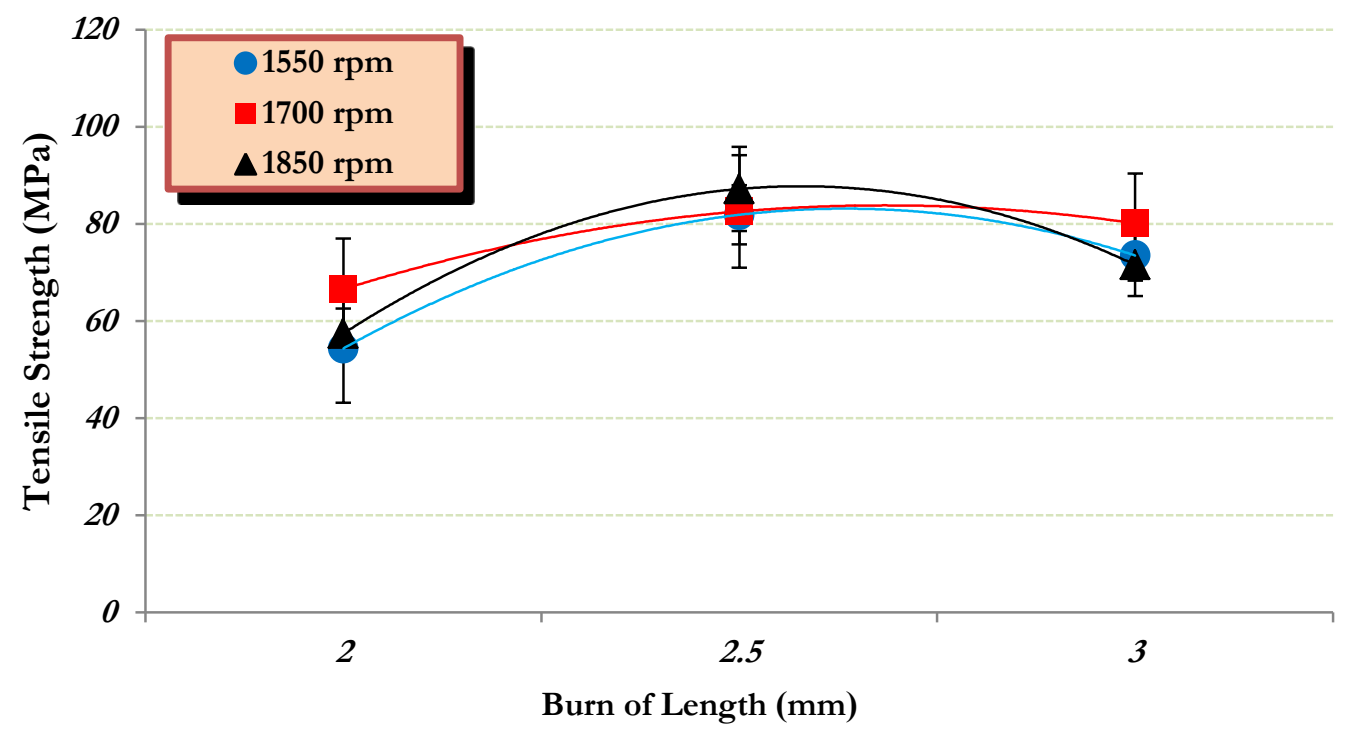

Fig. 6. Tensile strength of SSM356 with SSM6061 aluminum alloy by RFW process.

\subsection{Hardness Value}

The hardness test by Vicker's microhardness method with burn-off length at $2 \mathrm{~mm}$ was illustrated in Fig. 7 (a), with burn-off length at $2.5 \mathrm{~mm}$ was illustrated in Fig. 7(b) and with burn-off length at $3 \mathrm{~mm}$ was illustrated in Fig. 7(c) respectively. According to the results, it was found that, in all burn-off length factor, the weld metal has the higher hardness in thermal mechanical affect zone and base metal because changes of microstructure and the distribution of $\mathrm{Mg}_{2} \mathrm{Si}$ phase make a good compressive force. When we compared among the rotation speed in weld metal, it showed that the average hardness was $74.20 \mathrm{HV}$ at $1700 \mathrm{rpm}$ while the rotation speeds at 1550 and $1850 \mathrm{rpm}$ produced 63.83 and $65.56 \mathrm{HV}$ respectively. Meanwhile, the hardness of base SSM356 aluminum alloy was $61.42 \mathrm{HV}$ (as cast) and $53.79 \mathrm{HV}$ from base SSM6061 aluminum alloy (as cast). The heat input was created by the friction between workpiece surfaces causing the weld metal to change their microstructure. Although the weld metal has high heat input during welding [22], the thermal mechanical affect zone is the area where heat transfers from the weld metal to the base metal. As a result, the hardness is higher than the base metal but less than welds metal [23]. For example, for the rotation speeds at $1850 \mathrm{rpm}$ and burn-off length at $2.5 \mathrm{~mm}$, it produced $61.52 \mathrm{HV}$ in SSM356 aluminum alloy side and $51.84 \mathrm{HV}$ in SSM6061 aluminum alloy side. However, hardness properties of base metals of the workpiece were unchanged because they are not affected by the heat generated while welding. The heat is important for RFW process because it affects the hardness properties and adhesion of the workpiece.
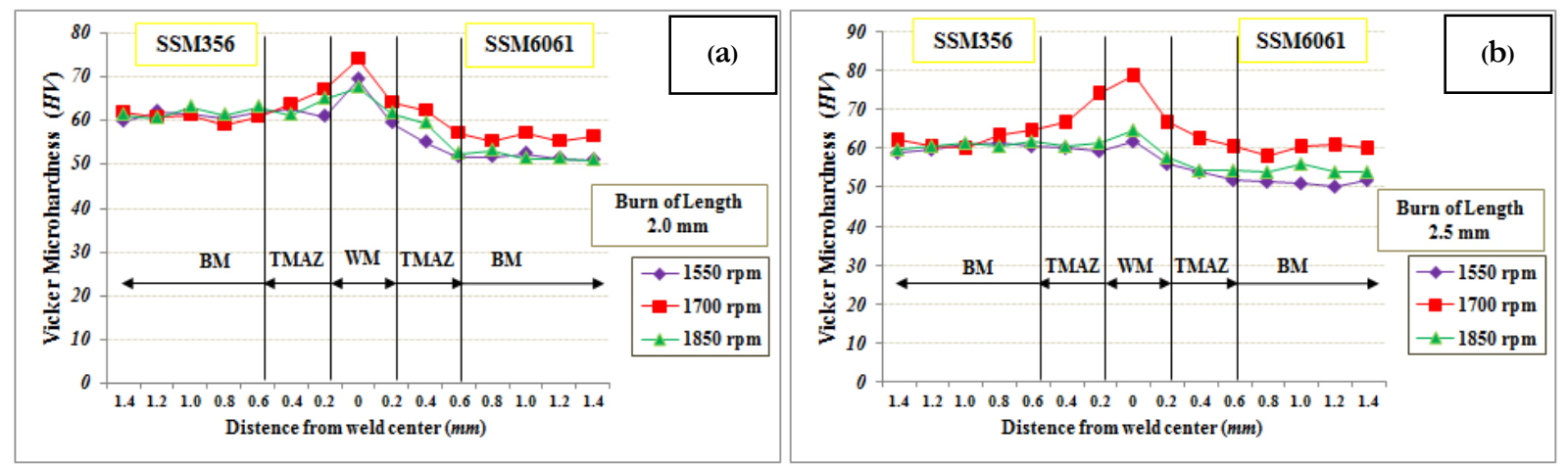


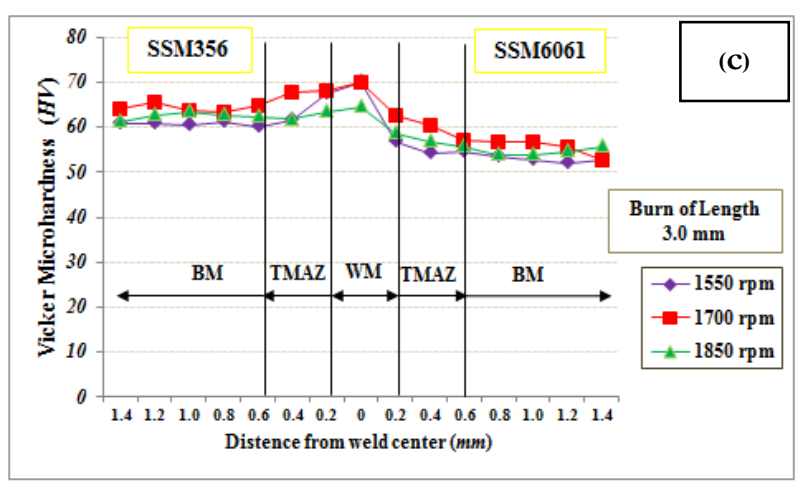

Fig. 7. Vicker microhardness properties of workpeices at different rotation speeds. (a) $2 \mathrm{~mm}$ burn-off length, (b) $2.5 \mathrm{~mm}$ burn-off length, and (c) $3 \mathrm{~mm}$ burn-off length.

\subsection{Effects of Rotation Speed and Burn-off Length Affecting the Tensile Strength}

The RFW process between different materials for this experiment is semi-solid casted aluminum grades SSM356 and SSM6061. The researchers have conducted tensile strength test for General Full Factorial Design consisting of two factors [24]: speed and burn-off length. There are three level variables for each factor in order to make the appropriate sample size. The strength of the effect size of 0.95 confidence level tested at $45 \mathrm{MPa}$ and a standard deviation of 10.45 make them a suitable sample size for 3 to perform in this experiment. As illustrated in Fig. 8.

\section{Power and Sample size}

$$
\begin{aligned}
& \text { General Full Factorial Design } \\
& \alpha=0.05 \text { Assumed Standard Deviation }=10.45
\end{aligned}
$$

Factors: 2 Number of Level 3

Include terms in the model up through order: 1

Not including blocks in model.

$\begin{array}{rccrr}\text { Maximum } & & \text { Total } & \text { Target } & \\ \text { Difference } & \text { Reps } & \text { Runs } & \text { Power } & \text { Actual Power } \\ 45 & 3 & 9 & 0.90 & 0.953514 \\ 45 & 3 & 9 & 0.95 & 0.953514\end{array}$

Fig. 8. A suitable size of samples for this test.

The data obtained from the General Full Factorial Design experiment were brought to repeatedly test for the tensile strength for three times. The results were statistically analysed and must be checked for accuracy according to General Full Factorial Design conditions including normality value, constant variance, and independence. It was found that there was no sufficient evidence to support the conclusion that the data are not normally distributed. For residual (analysis) variability test, it was found that there was no sufficient evidence to conclude that there was no significant difference in the variability of the tensile strength among all experiments. Also, according to data independence, it was found that no clear evidence was related to the residual value of any pattern or trend as illustrated in Fig. 9. Therefore, it can be concluded that the General Full Factorial Design is an appropriate condition. 


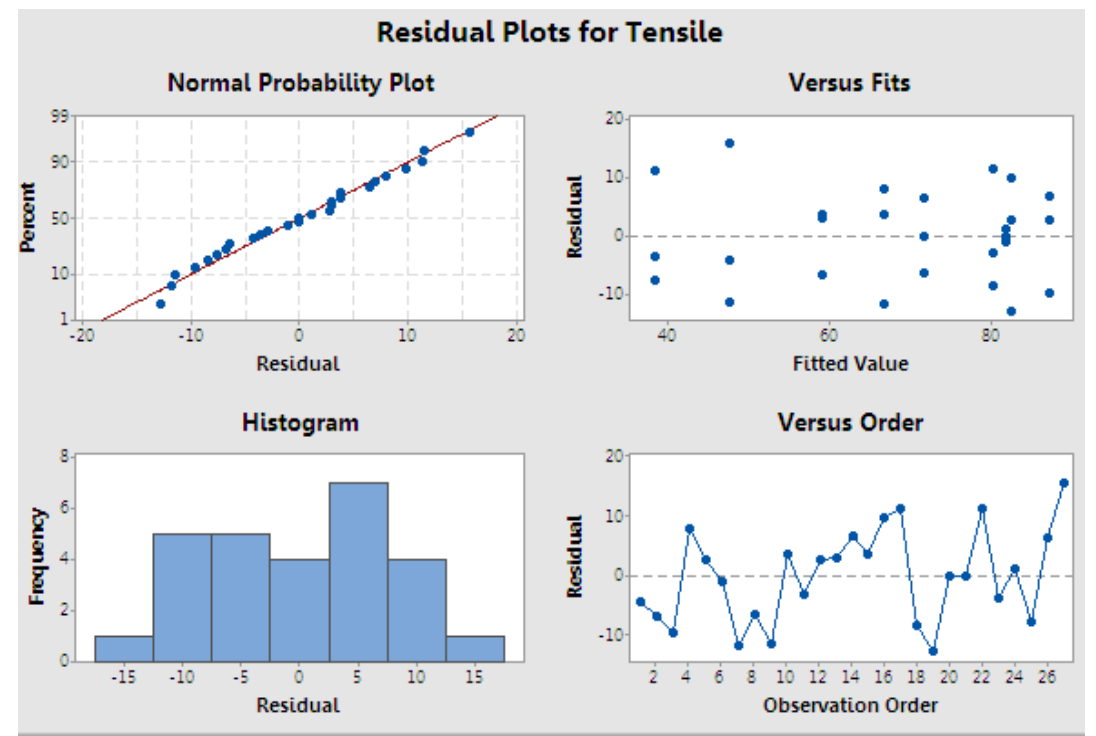

Fig. 9. Data validation and data accuracy.

According to Table 3, analysis of variance showed that the speed factor and burn-off length was significantly influence the tensile strength, with a p-value less than 0.05 . Coefficient of determination Rsquare is equal to 81.40 percent. It means that the variations of the experiments are controllable, such as equipment or other factors in the experiment. These variables were set to 81.40 percent. For the remaining, only 18.60 percent was uncontrollable factors.

Table 3. Analysis of Variance (ANOVA).

\begin{tabular}{llllll}
\hline \multicolumn{1}{c}{ Source } & DF & Adj SS & Adj MS & F-value & p-value \\
\hline Rotation speed & 2 & 1268 & 633.98 & 7.14 & 0.005 \\
Bern of length & 2 & 3436 & 1718.02 & 19.35 & $<0.0001$ \\
Rotation speed*Burn-off length & 4 & 2289 & 572.16 & 6.44 & 0.002 \\
Error & 18 & 1598 & 88.78 & & \\
Total & 26 & 8591 & & & \\
\hline & & & & &
\end{tabular}

R-sq $=81.40 \%$ R-sq(adj) $=73.13 \%$

\section{Conclusion}

The parameters affect tensile strength and hardness properties of dissimilar joining SSM356 aluminum alloys with SSM6061 aluminum alloys by using RFW can be concluded that the higher burn-off length and the higher rotation speed, the better significant welding quality of the workpeices we have. In addition, friction force resulting compound of $\mathrm{Mg}_{2} \mathrm{Si}$ phase leads to plastic deformation, the particle size of $\mathrm{Mg}_{2} \mathrm{Si}$ phase become smaller. The higher tensile strength and microhardness within weld metal and thermal mechanical affect zone are caused from the higher rotation speed and higher burn-off length.

\section{Acknowledgements}

This work was financially supported by research contract No.60/2557 from the Institute of Research and Development, Songkhla Rajabhat University, Thailand.

\section{References}

[1] A. Z. Sahin, B. S. Yibas, M. Ahmed, and J. Nickel, "Analysis of the friction welding process in relation to the welding of copper and steel bars," Journal of Materials Processing Technology, vol. 82, no. 1/3, pp. 127-136, 1998. 
[2] M. Aritoshi and K. Okita, "Friction welding of dissimilar metals," Welding International, vol. 17, no. 4, pp. 271-275, 2003.

[3] K. Boonseng, C. Meengam, S. Chainarong, and P. Muangjunburee, "Microstructure and hardness of friction welded SSM 356 aluminium alloy," Advanced Materials Research, vol. 887-888, pp. 1273-1279, 2014.

[4] R. Kumar and M. Balasubramanian, "Application of response surface methodology to optimize process parameters in friction welding of Ti-6Al-4V and SS304L rods," Transactions of Nonferrous Metals Society of China, vol. 25, pp. 3625-3633, 2013.

[5] Z. Liang, G. Qin, L. Wang, X. Meng, and F. Li, "Microstructural characterization and mechanical properties of dissimilar friction welding of 1060 aluminum to AZ31B magnesium alloy," Materials Science and Engineering A, vol. 645, pp. 170-180, 2015.

[6] M. Srinivasan, C. Loganathan, V. Balasubramanian, Q. B. Nguyen, M. Gupta, and R. Narayanasamy, "Feasibility of joining AZ31B magnesium metal matrix composite by friction welding," Materials and Design, vol. 32, pp. 1672-1676, 2011.

[7] M. Kimura, A. Fuji, and S. Shibata, "Joint properties of friction welded joint between pure magnesium and pure aluminium with post-weld heat treatment," Materials and Design, vol. 85, pp. 169-179, 2015.

[8] M. B. Uday, M. N. Ahmad Fauzi, H. Zuhailawati, and A. B. Ismail, "Evaluation of interfacial bonding in dissimilar materials of YSZ-alumina composites to 6061 aluminium alloy using friction welding," Materials Science and Engineering A, vol. 528, pp. 1348-1359, 2011.

[9] M. B. Uday, M. N. Ahmad Fauzi, H. Zuhailawati, A. B. Ismail, "Effect of welding speed on mechanical strength of friction welded joint of YSZ-alumina composite and 6061 aluminum alloy," Materials Science and Engineering A, vol. 528, pp. 4753-4760, 2011.

[10] M. N. Ahmad Fauzi, M. B. Uday, H. Zuhailawati, and A. B. Ismail, "Microstructure and mechanical properties of alumina-6061 aluminum alloy joined by friction welding," Materials and Design, vol. 31, pp. 670-676, 2010.

[11] H. Khalid Rafi, G. D. Janaki Ram, G. Phanikumar, and K. Prasad Rao, "Microstructure and tensile properties of friction welded aluminum alloy AA7075-T6," Materials and Design, vol. 31, pp. 2375-2380, 2010.

[12] M. B. Uday and M. N. Ahmad-Fauzi, "Joint properties of friction welded 6061 aluminum alloy/YSZalumina composite at low rotational speed," Materials and Design, vol. 59, pp. 76-84, 2014.

[13] W. Li, S. Shi, F. Wang, Z. Zhang, T. Ma, and J. Li, "Numerical simulation of friction welding processes based on ABAQUS environment," Journal of Engineering Science and Technology Review, vol. 5, no. 3, pp. 10-19, 2012.

[14] X. Wang, F. Lu, H.-P. Wang, H. Cui, X. Tang, and Y. Wu, "Mechanical constraint intensity effects on solidification cracking during laser welding of aluminum alloys," Journal of Materials Processing Technology, vol. 218, pp. 62-70, 2015.

[15] S. Mercan, S. Aydin, and N. Ozdemir, "Effect of welding parameters on the fatigue properties of dissimilar AISI 2205-AISI 1020 joined by friction welding," International Journal of Fatigue, vol. 81, pp. 78-90, 2015.

[16] M. Sahin, H. E. Akata, and T. Gulmez, "Characterization of mechanical properties in AISI 1040 parts welded by friction welding," Materials Characterization, vol. 58, pp. 1033-1038, 2007.

[17] R. Burapa, S. Janudom, T. Chucheep, R. Canyook, and J. Wannasin, "Effects of primary phase morphology on mechanical properties of $\mathrm{Al}-\mathrm{Si}-\mathrm{Mg}$-Fe alloy in semi-solid slurry casting process," Transactions of Nonferrous Metals Society of China, vol. 20, pp. s857-s861, 2010.

[18] S. K. Singh, K. Chattopadhyay, G. Phanikumar, and P. Dutta, "Experimental and numerical studies on friction welding of thixocast A356 aluminum alloy," Acta Materialia, vol. 73, pp. 177-185, 2014.

[19] I.-D. Park, C.-T. Lee, H.-S. Kim, W.-J. Choi, and M.-C. Kang, "Structural considerations in friction welding of hybrid $\mathrm{Al}_{2} \mathrm{O}_{3}$-reinforced aluminum composites," Transactions of Nonferrous Metals Society of China, vol. 21, pp. s41-s46, 2011.

[20] L. Donatia, E. Troiania, P. Prolia, and L. Tomesani, "FEM Analysis and experimental validation of Friction Welding process of 6xxx alloys for the prediction of welding quality," Materials Today: Proceedings, vol. 2, pp. 5045-5054, 2015.

[21] Y.-L. Song, Y.-H. Liu, X.-Y. Zhu, S.-R. Yu, and Y.-B. Zhang, "Strength distribution at interface of rotary-friction-welded aluminum to nodular cast iron," Transactions of Nonferrous Metals Society of China, vol. 18, pp. 14-18, 2008. 
[22] A. Moarrefzadeh, "Numerical modeling of friction welding process," International Journal of Multidisciplinary Sciences and Engineering, vol. 2, no. 8, pp. 47-51, 2011.

[23] M. Kaczorowski, O. Goroch, and A. Krzynska, "The mechanism of solid state joining THA with $\mathrm{AlMg}_{3} \mathrm{Mn}$ alloy," Archives of Foundry Engineering, vol. 14, no. 2, pp. 37-42, 2014.

[24] D. C. Montgomery, Designing and Analysis of Experiments, 5th ed. New York: John Wiley \&Sons Inc., 2000. 